\title{
O DIREITO À ESPERA DA LEI
}

1 - Eficácia da norma constitucional. 2 - Eficácia imediata e eficácia diferida. 3 - Procedimentos especiais sobre inércia legislativa mandado de injunção e ação de inconstitucionalidade por omissão. 4 - Jurisprudência do Supremo Tribunal Federal. 5 - Mandado de injunção e injunction.

O tema que nos propomos a desenvolver tem como objeto os novos instrumentos que a jovem Constituição brasileira de 1988, cujo segundo aniversário se aproxima, acrescentou ao elenco de meios judiciais de afirmação de direitos e liberdades.

O título da palestra visa a aliciar o interesse dos leigos, destacando o contraste entre as normas programáticas da Constituição e a efetiva fruição de seus benefícios pelos destinatários.

No plano constitucional, certas normas produzem efeitos imediatos e diretos. Outras há em que a conceito enunciado fica a depender de lei que torne realidade o comando abstrato. No primeiro caso ter-se-á a aplicabilidade imediata do preceito que assegura o direito ou liberdade: o seu titular goza, de plano, dos efeitos que the são atribuídos. Na segunda hipótese, diz-se que a norma constitucional é de aplicabilidade diferida ou retida no sentido de que o direito ou liberdade que existe potencialmente, não opera até que a lei regule o seu exercício. Em tal caso, podemos dizer que o direito em estado latente espera a lei que deflagre sua eficácia.

A mais frequiente expressão desse condicionamento resulta da própria redação da norma constitucional que se reporta ao gozo do direito ou da liberdade "nos termos da lei", ou "na forma da lei". Não somente sob essa forma expressa se verifica, porém, a limitação constitucional. A necessidade de lei complementar e integrativa poderá resultar implicitamente da formulação com que o direito ou liberdade é enunciado. De qualquer forma, em um caso ou outro, a lei, que se faz necessária, opera no sentido de libertar o direito ou liberdade preexistente, gerando efeitos até então contidos na expectativa da ação do legislador. 
Poder-se-á dizer que a ordem jurídica, em tais circunstâncias, opera em ritmo de dois tempos: a Constituição afirma o direito ou liberdade, mas a lei é que o converte em realidade.

Assim, o artigo $5^{\circ}$ da atual Constituição arrola um conjunto de direitos individuais e coletivos, discriminados em setenta e sete alíneas sucessivas. Muitos deles passaram a vigorar imediatamente após a promulgação, em favor de seus destinatários.

Contudo, à luz do interesse público — que tem como tradução o chamado poder de polícia - a Constituição pode transferir ao legislador a competência para determinar a oportunidade, ou o alcance, de determinada espécie de direito ou liberdade.

Por exemplo, a alínea VI do art. $5^{\circ}$ declara inviolável a liberdade de consciência e de crença, assim como o livre exercício de cultos religiosos, mas a proteção aos locais, de culto e às liturgias será garantida, na forma da lei, ou seja, ajustando-se o direito individual aos interesses superiores da comunidade, que a lei deverá amparar.

A aplicabilidade de um direito constitucional estará, em outros casos, virtualmente declarado, aguardando, porém, que a lei o coloque em movimento.

Tomemos outro exemplo no texto constitucional.

$\mathrm{O}$ mesmo artigo $5^{\circ}$ determina, em seu item XXXII, que o Estado "promoverá a defesa do consumidor". Qualifica, no entanto, a norma que essa atividade estatal especifica será feita "na forma da lei", posto que importa restrição de outros direitos igualmente respeitáveis de produtores ou comerciantes.

Devolve-se, conseqüentemente, ao legislador indicar o procedimento a ser adotado pela autoridade pública, que não poderá agir espontaneamente, a seu livre critério. É mister a intervenção do legislador que, na hipótese, acaba de regular a matéria na recente Lei $\mathrm{n}^{\circ} 8.078$, de 11 de setembro corrente, publicada há pouco mais de uma semana.

A atual Constituição, mais abundante que as anteriores, incorporou aos direitos e liberdades constitucionais, diversas figuras novas e elevou ao plano superior outras que apenas constavam da legislação ordinária.

Por isso mesmo se tornou mais numerosa a relação de normas de aplicabilidade diferida, à espera da lei que as torne efetivamente operantes.

O Ministério da Justiça publicou, em 1989, extenso volume de 510 páginas, sob o título expressivo de Leis a elaborar. E, em exaustiva pesquisa, indica 256 casos em que o texto constitucional expressamente requer legislação integrativa e outros 87 preceitos que facilmente exigem complementação legal.

Portanto, em 343 situações específicas a eficácia da norma constitucional estará contida até que o Congresso Nacional se manifeste.

Em verdade, a paralisia cia Constituição não é tão grave como tais números aparentam. Muitos do direitos e liberdades que desse modo se vinculam à presença de lei disciplinadora já se encontram reguladas em leis anteriores à Constituição.

$\mathrm{Na}$ medida em que tais leis forem compativeis com o ditame constitucional superveniente, não se interrompe sua eficácia no tempo. Continuam dotadas de força obrigatória, dizendo-se, conforme o jargão técnico, que são "recebidas" pela Constituição como se fossem leis novas em atenção ao princípio da continuidade da ordem jurídica. 
Somente as leis ou normas que, válidas perante a Carta Magna anterior, se tornarem incompatíveis com a Constituição sobrevinda, estarão revogadas pelo conflito com a nova sistemática constitucional.

Até a vigência da atual Constituição, as disposições condicionadas ao advento de lei reguladora permaneciam in fieri, no limbo a que estavam remetidas, sem remédio que as pudesse dinamizar. Não são poucos os direitos constitucionais que atravessaram a duração das Cartas precedentes sem alcançar a plenitude de sua vitalidade.

O constituinte procurou dar remédio contra a mora ou inércia do legislador, instituindo dois procedimentos especiais para suprir-lhes a inoperância: o mandado de injunção e a ação de inconstitucionalidade por omissão.

São criações peculiares, de contornos próprios, ainda que inspiradas no direito comparado, que, todavia, não foram transpostas integralmente de modelos estrangeiros.

Visando, em última análise, ao mesmo fim - o de remover a inatividade do legislador —, têm, no entanto, específica destinação. O primeiro deles, o mandado de injunção, legitima o titular de um direito ou liberdade, a reclamar contra a inércia que o impede do efetivo gozo do favorecimento da norma constitucional. Na segunda modalidade — a da ação de inconstitucionalidade por omissão — não mais se cuida da proteção de um direito ou liberdade individual concreta, mas do suprimento da lei em tese, necessário à complementação da norma constitucional.

A declaração de inconstitucionalidade por omissão (a que alude o $\S 2^{\circ}$ do artigo 103 da Constituição), de competência do Superior Tribunal Federal, tem como símile próximo a Constituição de Portugal, que dispõe, em termos equivalentes, no artigo 283, da Constituição revista em 1989 (antes o preceito figurava no artigo de igual número do primeira revisão de 1982 e no artigo 279 do texto original de 1976). $\mathrm{Na}$ primeira versão, o Conselho da Revolução era autorizado a recomendar aos órgãos legislativos competentes a emissão, em tempo razoável, da medida necessária a tornar exequível a norma constitucional. Nas revisões que se sucederam, tão-somente se especifica a competência do Tribunal Constitucional para verificar a existência da inconstitucionalidade por omissão, do que dará conhecimento do órgão legislativo.

A este último modelo aderiu a Assembléia Constituinte, conforme o mencionado preceito da Constituição promulgada em outubro de 1988:

"Declarada a inconstitucionalidade por omissão de medida para tornar efetiva norma constitucional, será dada ciência ao Poder competente para a adoção das providências necessárias e, em se tratando de órgão administrativo, para fazê-lo em trinta dias."

Contempla, em suma, a disposição constitucional tanto a inércia legislativa, como a do poder regulamentar, não lhes fixando porém, prazo para o suprimento da lacuna. Se, contudo, a mora for imputável a autoridade administrativa, competente para editar ato de teor normativo, fica-lhe assinado o trintídio para observância da decisão judicial.

A mais relevante novidade da Constituição de 1988 é, contudo, a criação de um novo remédio, que se vem somar ao mandado de segurança em defesa dos direitos e liberdades públicas. 
Nos termos do item LXXXI do artigo 59, "conceder-se-á mandado de injunção sempre que a falta de norma regulamentadora torne invariável o exercício dos direitos e liberdades constitucionais e das prerrogativas inerentes à nacionalidade, à soberania e à cidadania."

Algumas questões de logo afloram à compreensão do texto.

Primeiramente, a latitude do preceito alcança tanto os direitos e a liberdades relacionados no próprio artigo $5^{\circ}$ ou seja, direitos individuais e coletivos, como por extensão os direitos sociais, objeto do artigo $7^{\circ}$, que são igualmente direitos constitucionais.

De outra parte, a menção a prerrogativas inerentes à soberania, deverá ser entendida com respeito à soberania popular, regulada no artigo 14 da Constituição (não cuida, obviamente, da soberania tout court, que é prerrogativa do Estado Nacional, nas relações internacionais).

Por último, a referência à falta de norma regulamentadora, se dirige tanto à mora legislativa como à inércia dos demais órgãos dotados de poder normativo, embora secundário.

O procedimento próprio do mandado de injunção deverá ser, objeto de lei processual específica. Todavia, o Supremo Tribunal Federal já firmou jurisprudência no sentido de que, até que esta venha a ser editada, cumprir-se-á, por analogia, o rito estabelecido para o mandado de segurança.

Em dois momentos a Constituição prevê a competência para julgar mandados de injunção. Quando a omissão for imputável ao Presidente da República, ao Congresso Nacional ou a Tribunais Superiores da União a jurisdição pertence ao Supremo Tribunal Federal. E o Superior Tribunal de Justiça quando a elaboração da norma regulamentadora for atribuição de outro órgão, entidade ou autoridade federal da administração federal, direta ou indireta.

$\mathrm{E}$ as Constituições Estaduais cumpre atribuir a correspondente competência aos Tribunais de Justiça para conhecimento e julgamento de mandados de injunção.

Em que deve consistir a manifestação do Poder Judiciário diante de comprovada omissão do legislador, ou autoridade competente, em emitir norma regulamentadora de direito ou liberdade constitucional?

O Supremo Tribunal Federal, em reiteradas decisões, tem adotado posição conservadora sobre a matéria.

Conforme paradigma firmado em decisão no Mandado de Injunção $\mathrm{n}^{\circ} 107$, proferida em sessão de 23 de novembro de 1989 , reconheceu que o mandado de injunção tem exclusiva natureza mandamental e declaratória: não condena, nem ordena, nem supre a inércia reconhecida.

Em síntese que exprime a posição da Corte Suprema, afirmou-se que "o mandado de injunção nem autoriza o Judiciário a suprir a omissão legislativa ou regulamentar, editando o ato normativo omitido, nem, menos ainda, lhe permite ordenar, de imediato, ato concreto de satisfação do direito reclamado".

O mandado de injunção, consoante o entendimento consagrado na jurisprudência do Supremo Tribunal Federal, "se destina a obter sentença que declare a ocorrência da omissão constitucional, com a finalidade de que se dê ciência ao omisso dessa 
declaração, para que adote as providências necessárias, à semelhança do que ocorre com a ação direta de inconstitucionalidade por omissão".

Em julgamento recente, o Supremo Tribunal Federal enfrentou, no Mandado de Injunção $n^{\circ} 219$, decidido em sessão de 22 de agosto último, a pretensão de deputados, em pedido encabeçado pelo Deputado José Serra, no sentido de que a bancada do Estado de São Paulo fosse aumentada, com base no $\$ 19$ do artigo 45 da Constituição, na ausência de lei complementar que devia observar a sua proporcionalidade com a população. Embora expressamente reconhecendo a omissão em que se encontra o Congresso Nacional quanto à elaboração da lei complementar, recusou-se a Suprema Corte a determinar o requerido aumento quantitativo, limitando-se a deferir, em parte, o pedido para dar ciência ao Congresso Nacional da situação de mora constitucional, para que supra a omissão em tempo hábil.

Não tem sido esta a interpretação que ilustres processualistas têm atribuído a novo instrumento constitucional. Celso Agrícola Barbi, Adhemar Ferreira Maciel e Celso Bastos sugerem que o juiz, aplicando princípio de eqüidade, deve resolver o caso concreto, adotando medida satisfativa do pedido do autor (Mandados de Segurança e de Injunção, coletânea de estudos, edição Saraiva, p. 377, 378 e 391).

O emérito Professor e Desembargador José Carlos Barbosa Moreira, em estudo destinado ao Anuário de Direito Brasileiro, em curso de publicação, filiou-se à mesma posição e a defendeu em artigo inserido no Jornal do Brasil de 11 do corrente mês, sob o título "S. O. S. para o mandado de injunção".

Entre solução alternativas, adoto a que the parece mais condizente com a finalidade do writ constitucional:

“o órgão judicial formula a 'norma regulamentadora' que falta e aplica-a ao caso concreto, assegurando assim - nos estritos limites deste - o exercício do direito ou liberdade constitucional, ou da prerrogativa inerente à nacionalidade, à soberania e à cidadania."

Contrastam essas opiniões doutrinárias com a constante afirmativa do Supremo Tribunal Federal de que "o mandado de injunção não defere ao Poder Judiciário substituir o legislador, suprindo, em lugar dele, a lacuna normativa; nem propicia a edição de ato concreto de satisfação do direito reclamado" (despacho do Ministro Sepúlveda Pertence no Mandado de Injunção $n^{\circ} 168$ ). A mesma linha de pensamento tem sido expressa por outros Ministros, porque, nos termos de despacho do Ministro Celso de Mello, "a própria excepcionalidade desse novo instrumento jurídico impõe ao Judiciário o dever de estrita observância do princípio constitucional da divisão funcional de poderes" (Mandado de Injunção $n^{\circ} 191-D J$ de 1.2.90).

A nosso ver a prudente orientação do Supremo Tribunal Federal é, realmente, a mais fiel ao espírito e ao sistema da Constituição.

Quando o legislador constituinte deixa de tornar auto-aplicável determinado preceito atributivo de direito ou liberdade, para subordiná-lo a uma explicitação do Poder Legislativo, está concedendo ao Congresso Nacional um poder discricionário, de teor eminentemente político, com respeito à oportunidade e conveniência da efetiva eficácia do conteúdo da norma e da extensão a que ela deverá obedecer.

$O$ juiz, até mesmo pela insuficiência do domínio técnico ou fático da matéria, não dispõe nem de poder, nem de saber, que lhe possibilite agir, adequadamente, 
substituindo o legislador ou o administrador. Mais ainda se faz imprópria a solução judicial casuística, quando afastará, na diversidade de julgamentos, o caráter de generalidade próprio da norma legislativa, que elide a discriminação de tratamento entre iguais situações.

A jurisprudência do Supremo Tribunal Federal, chamado com frequiência a decidir pedidos de mandado de injunção, tem consolidado, ainda, outros pontos relevantes na construção do remédio constitucional, ainda pendente de lei processual própria.

Como o pressuposto da medida excepcional é a "falta de norma regulamentadora", o Tribunal se exime de conhecer os mandados de injunção, quando o processo de elaboração legislativa, embora não concluído, já se iniciou com a apresentação de projetos de lei, de iniciativa do Presidente da República ou de parlamentares. A lei em curso de elaboração descaracteriza a mora legislativa.

Também exige-se, como requisito de legitimidade ativa para pleitear, que o autor seja titular de direito próprio que esteja impedido de exercer, ou usufruir, em razão da inércia do legislador.

É mister, ainda, que, tal como no mandado de segurança, o impetrante ofereça no pedido inicial prova preconstituída da situação de fato que evidencie a titularidade do direito, liberdade ou prerrogativa que a ausência de norma torne inviável.

O mandado de injunção, tal como concebido na Constituição brasileira, não se assemelha, nem tem como fonte, o instituto da injunction, de antiga presença no direito inglês c norte-americano.

Nascida como um remédio de equiidade, a injunction tem ali a natureza de uma ordem para que alguém se abstenha de uma conduta ilícita que ofende ou impede o exercício regular de direito, impondo-se-lhe uma obrigação de dar ou fazer (mandatory injunction), ou uma obrigação de não fazer (prohibitory injunction). A ordem judicial obriga o réu a determinado modo de agir e a desobediência submete o infrator a sanções pecuniárias ou mesmo prisão por desrespeito à Justiça (contempt of court).

Historicamente, no famoso caso Debs, decidido em 1894, dirigentes sindicais foram competidos a não usar de violência como processo de realização de greves em estradas, de ferro, em prejuízo do comércio interestadual. Em termos atuais, o remédio de injunction foi largamente usado em defesa de direitos civis de modo a impedir a segregação racial, quando a discriminação contra candidatos negros em matrículas nas escolas do Alabama ofendia o princípio de igualdade perante à lei. De igual modo, o tratamento injusto em prisões ou estabelecimentos de doentes mentais motivou ordens judiciais, que, vedando atos discriminatórios, preservam direitos dos presos ou dos internados.

A doutrina e a jurisprudência sobre o mandado de injunção, como sobre a ação de inconstitucionalidade por omissão mal começam a ser delineadas em seus contornos. Na medida em que o Congresso Nacional, cumprindo seu dever constitucional, suplemente a Constituição, editando as leis necessárias a tornar eficientes os direitos e liberdades que delas dependam, o mandado de injunção ficará restrito ao papel excepcional que lhe está reservado.

E pela demora no regular desempenho de sua função precípua de legislar que o Congresso Nacional contribui, omissivamente, para que a pressão sobre o Poder Ju- 
diciário se torne mais constante e veemente na postulação de uma forma substitutiva da inércia legislativa.

Direitos e liberdades constitucionais que atravessam o tempo sem real eficácia representam um desestímulo do Estado Democrático de Direito, que a Constituição coloca, em seu preâmbulo, como finalidade essencial de sua estrutura.

Não será porém, na ampliação de poderes do Judiciário, implantando o que se chamou, em certa fase da experiência norte-americana, de Governo dos Juízes, que se poderá encontrar a fórmula mais propícia e adequada para fortalecer e vivificar os direitos e liberdades constitucionais programados na letra e no espírito da Constituição. 


\section{Responsabilidade Civil dos Pais pelos Actos dos Filhos Menores}

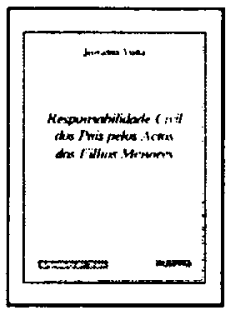

\author{
Jeovanna Viana \\ Ref. 0490 \\ Brochura \\ 292 págs. \\ Form. $13,5 \times 21$ \\ 2004 \\ ISBN $85-7147-415-8$
}

A obra tem como eixo central a legislação portuguesa, não deixando entretanto de acrescentar em todos os pontos abordados um estudo comparado com o direito brasileiro, direito anglo-saxônico e direito europeu. A gramática de Portugal foi utilizada para redigir o trabalho, tendo em vista estarmos tratando do mesmo idioma não acreditamos ser necessária a conversão do texto para a gramática do Brasil.

\section{Responsabilidade Civil do Estado Intervencionista}

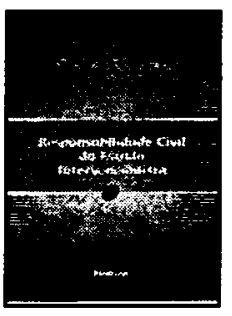

\section{Fernando Facury Scaff}

Ref. 0323

Brochura

306 págs.

Form. $14 \times 21$

$2001 / 2^{2} \mathrm{ed}$.

ISBN 85-7147-261-0

Apresenta uma nova visão acerca da responsabilidade do Estado, não mais alinhada apenas com os tradicionais e usuais campos de estudo, mas sim vinculada à intervenção do Estado na economia. Fruto de uma tese de doutorado defendida na USP, foi amplamente modificada e atualizada com a intenção de se adequar à nova realidade constitucional e ao crescente papel do Estado como agente regulador da atividade econômica.

\section{Responsabilidade Civil e o Novo Código Civil}

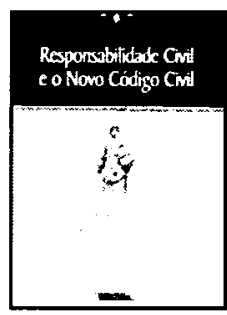

\section{Antônio Elias de Queiroga}

Ret. 0434

Brochura

294 págs.

Form. $14 \times 21$

$2003 / 2^{\mathrm{a}} \mathrm{ed}$

ISBN 85-7147-375-7

Entre vários pontos explorados, destaca-se: 0 momento em que a obrigação de indenizar é examinada em todos os seus aspectos, por enfrentar as controvérsias geradas com as atividades geradas com as atividades de risco, com a responsabilidade decorrente por ato de incapaz, por fato de terceiro e quando imposta aos pais por ações de filhos menores.

\section{Responsabilidade Civil no Direito Comparado}

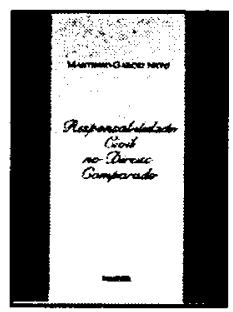

\section{Martinho Garcez Neto}

Ref. 0256

Brochura

226 págs.

Form. $14 \times 21$

2000

ISBN 85-7147-160-6

Aponta as distinçōes entre a responsabilidade subjetiva e a objetiva, mostrando como evoluíram a teoria da culpa e a do risco; analisa os fatos geradores ou excludentes da responsabilidade reparatória, examinando seus elementos, estabelecendo os conceitos de ato ilícito e de dano, as figuras do estado de necessidade, da legitima defesa, dos abusos de direito e dos atos emulativos, e estudando 0 nexo causal, incluído o delicado problema de sua comprovaçāo. 